\title{
Assessment of Mothers' Knowledge Regarding Care of Children Connected with Permanent Pacemaker
}

\author{
SEHAM Y. ZEDAN, M.Sc.; SOHEIR A. MOHAMED, D.N.Sc. and MARWA A. IBRAHIM, D.N.Sc.
}

The Department of Pediatric Nursing, Faculty of Nursing, Cairo University

\begin{abstract}
Background: Permanent pacemaker is a small batterypowered medical device designed to electrically stimulate the heart muscle in an effort to restore the heart rhythm towards normal. Pediatric pacemaker implantation is performed to treat abnormalities of Sinoatrial (SA) node.

Aim of Study: To assess mothers' knowledge regarding care of children connected with permanent pacemaker.

Subjects and Methods: A descriptive research design was utilized. A convenient sample of 50 mothers of children under five years have implanted permanent pacemaker were participated in the study. The study was conducted in the arrhythmia out-patient clinic at the Preventive Medicine and Social Center, affiliated to Cairo University Hospitals. The required data was collected through structured interview questionnaire which developed by the research investigator to assess mothers' knowledge regarding care of children connected with permanent pacemaker.
\end{abstract}

Results: The results of the current study revealed that more than three quarters of the mothers had unsatisfactory level of knowledge regarding care of their children with permanent pacemaker, although, the majority of them obtained satisfactory level of reported care. There were statistically significant positive correlations between the total mean score of mothers' knowledge and reported care and their age, occupation, place of residence and level of education.

Conclusion: The results concluded that the highest percentage of the mothers had unsatisfactory level of knowledge regarding care of children connected with permanent pacemaker. It was recommended that raising the awareness of mothers about care of children connected with permanent pacemaker is mandatory through health education sessions about the pacemaker, child's activities and home pre cautions.

Key Words: Permanent pacemaker-Children under five years - Mothers' knowledge.

\section{Introduction}

THE heart has its own 'natural' pacemaker. There is a group of cells on the right side of the heart

Correspondence to: Dr. Seham Y. Zedan, The Department of Pediatric Nursing, Faculty of Nursing, Cairo University transmit regular electrical impulses across the two atria. The heart needs these electric signals to make it beat. Some children are born with an arrhythmia, when the heart beat is irregular, or too slow (for example bradycardia). Sometimes children develop an arrhythmia as a result of heart surgery because the pathway along which the electric signals travel has become blocked or damaged. To help maintain a steady, regular heartbeat an artificial pacemaker is implanted [1]. Implantation of cardiac pacemakers has been practiced for at least five decades with continuous developments of the hardware [2] .

A pacemaker is a small device that helps heart beats more regularly; it works with a small electric stimulation [3]. Pacemakers may be temporary or permanent, temporary pacemakers are intended for short-term use during hospitalization. Permanent pacemakers are intended for long-term use, is recommended for certain conditions that are chronic or recurrent and not due to a transient cause. Permanent pacing may be considered necessary or appropriate for certain patients with symptomatic bradyarrhythmia or, less commonly, to help prevent or terminate tachyarrhythmia [4].

The first pacemaker was implanted for children in the late 1960s. Pediatric pacemakers comprise less than $1 \%$ of all pacemaker implants [5]. Applying permanent pacing therapy for young children can be challenging. Many issues, such as child's size, body growth, and coexistence of congenital heart disease, have to be considered. Selecting the best pacing system for a child requires a firm understanding of modern pacing design, pacing indications, advantages and drawbacks of pericardial and endocardial lead pacing, and possible complications [6]

The most common indications for permanent pacemaker implantation in children are third-degree 
Atrioventricular (AV) block, either congenital or post-surgical. The indications for pacing in children with congenital AV block include heart rate $<55$ beats/minute in a neonate or $<40$ beats/minute in older children or adolescent, heart rate $<70$ beats/ minute in children with congenital heart defects. The indications for pacing related to non-congenital/surgical AV block include advanced secondor third-degree AV block associated with symptomatic bradycardia, ventricular dysfunction, or low cardiac output and postoperative advanced secondor third-degree AV block persisting for at least 710 days or not expected to resolve. In addition, pacemakers are used (though less commonly) for other disorders, such as congenital long QT syndrome and cardiomyopathy [7].

In an Egyptian study conducted by [8] on 32 children undergoing permanent pacemaker implantation. The study results concluded that permanent pacing in pediatric patients is generally safe and has a favorable long-term outcome, but there remains a high rate of complications, mainly related to leads dislodgement and infection. This is of particular concern in children who need a lifetime of pacing. They emphasized that, in pediatric pacing there are certain challenges that are not posed in adults like somatic growth, active life style, susceptibility to infection and the generally anticipated long survival.

Similarly, a studyheld by [9] to evaluate utilization trends, complication rates, and cost associated with pacemaker implantation in the pediatric population. The study findings revealed that the early complications of pacemaker were pneumothorax $(2.2 \%)$, hematoma (3.3\%), endocarditis/ pericarditis $(1.1 \%)$ and surgical infection $(2.4 \%)$. They emphasized that reduction in these complications would improve patient care and lower medical costs. Late complications rate in children was $37.5 \%$ of which were lead related complications or failures that necessitated re-intervention.

Special instructions and precautions should be followed while caring for children with permanent pacemakers. Strong magnetic fields will interfere with the pacemaker's ability to sense the heart's activity so Magnetic Resonance Imaging (MRI) scanning is not allowed (unless the pacemaker is an MRI safe pacemaker). Avoid airport security systems-the child or family should show his/her pacemaker card. Mobile phones should not be placed over the pacemaker area. Avoid placing magnets over the pacemaker area as this may alter the pre-programed pacemaker settings [10].
Nursing care for pediatric patients with pacemakers involves the monitoring and prevention of common complications, preventing dislodgement, and educating parents on the proper use and maintenance of the pacemaker. Care of children with permanent pacemakers requires sophisticated nursing knowledge and skills [11]. When a pacemaker is implanted, the education of the parents and child includes an explanation of the device, a description of the component parts, an explanation of the surgical procedure, and discharge teaching. Parents should be aware of which type of lead is in place in their child. Parents teaching include information about the signs and symptoms of infection, general wound care, and activity restrictions. On the same context, $[12,13]$ documented that the child with a pacemaker should live and play.

\section{Significance of study:}

The clinical indications and scope of utility of cardiac pacemaker among young children is increasing due to improved survival of children with congenital heart diseases, as well as advances in pacing technology [10]. Pediatric pacemaker implants comprise less than $1 \%$ of all pacemaker implants [5]. Since the first fully implanted pacemaker in October of 1960, more than 2 million people have benefit from pacemaker therapy [14]

According to the statistics department at the Preventive Medicine and Social Center (2016), the total number of children who were connected with permanent pacemaker from less than three years and attended for follow-up in the arrhythmia clinic was about 114 children. The number of children who are under five years was $65(57 \%)$.

Aim of the study:

The aim of the current study was to assess mothers' knowledge regarding care of children connected with permanent pacemaker.

\section{Research question:}

What is the mothers' knowledge regarding care of children connected with permanent pacemaker?

\section{Subject and Methods}

\section{Research design:}

A descriptive research design was utilized to achieve the aim of the current study. Descriptive research seeks to provide an accurate description of observations of phenomena. Descriptive research was "aimed at casting light on current issues or problems through a process of data collection that enables them to describe the situation more com- 
pletely than was possible without employing this method [15]. This design helps describe a situation or an event in exploring and knowing level of mother's knowledge regarding care of their children under five years connected with permanent pacemaker.

\section{Setting:}

The current study was conducted in the arrhythmia out-patient clinic at the Preventive Medicine and Social Center, affiliated to Cairo University Hospitals. The center provides preventive, therapeutic and socials services. The center includes various out-patients clinics and arrhythmia clinic. Arrhythmia clinic located at the third floor and received children connected with pacemaker every Wednesday for follow-up. Several children were referred to the pacemaker programming clinic at the fifth floor in Cairo University Specialized Pediatric Hospital (CUSPH) from June-Sept. 2016.

\section{Participants:}

A convenient sample of 50 mothers of children under five years have implanted permanent pacemaker was participated in the current study.

\section{Inclusion criteria:}

- Children under five years of age.

- Children connected with permanent pacemaker from less than three years.

- The mother is the main caregiver accompanied with the child.

\section{Ethical considerations:}

A primary approval was obtained from the Ethical Research Committee of the Faculty of Nursing, Cairo University to approve the study. The written informed consent was obtained from the mothers of children connected with permanent pacemaker after complete description of the purpose and the nature of the study. Children and their mothers were informed that participation in the study is voluntary. The research investigator also was informing the mothers about their rights to withdraw from the study at any time without giving any reason and without any effect on the care of their children. Confidentiality was assured to each child and their mothers. After completion of data collection, the final approval was obtained from the Research Ethical Committee in the Faculty of Nursing, Cairo University.

Data collection tool: The required data was collected through the following tool:

1- Structured interview questionnaire: It was developed by the research investigator in Arabic language after reviewing the related literature which containing fifty three (53) questions and consisted of four parts:

- Part 1: It involved five (5) questions related to the personal data about mothers as: Age, level of education, occupation, number of children and place of residence.

- Part II: It include eight (8) questions pertinent to the characteristics of children such as age, gender, rank in the family, enrollment to the kindergarten.... etc.

- Part III: It involved ten (10) questions related to the history of cardiac disease among children, time of pacemaker implantation ...etc.

- Part IV: It consisted of thirty (30) questions related to the mothers' knowledge about pacemaker and care provided for their children with permanent pacemaker such as definition, types, indications, possible complications, instructions and precautions, follow-up ...... etc.

\section{Scoring system:}

Scoring system for mothers' knowledge about pacemaker, each complete answer took two scores, incomplete one took one score and the wrong answer or no response took zero. The total score was converted to $100 \%$ (44 score) and then categorized as following: The total score of mothers' knowledge less than 50\% (<22) was considered as unsatisfactory while score of $50 \%$ and more (22 and more) was considered as satisfactory level of knowledge.

As regards mothers' reported care that provided for their children connected with permanent pacemaker, each complete care was taken two scores, incomplete one took one score and the wrong care or no response was took zero. The total score was converted to $100 \%$ (10 score) and then categorized as following: The total score of mothers' reported care less than $50 \%(<5)$ was considered as unsatisfactory while score of $50 \%$ and more (5 and more) was considered as satisfactory level of reported care.

\section{Validity and reliability:}

Data collection tool was reviewed by 5 experts in pediatric nursing and pediatric cardiology to test the content validity of tools. The tool was examined for content coverage, clarity, relevance, applicability, wording, length, format, and overall appearance. The experts agreed on the content of the tool, but recommended minor language changes that would make the information clearer and more 
precise. The suggested changes were made. Reliability of tools was performed to confirm its consistency using Cronbach's alpha and the results was reliability was 0.86 .

\section{Pilot study:}

Pilot study was conducted on $10 \%$ (5 mothers) of the total sample of mothers of children having permanent pacemakers to assess the feasibility, objectivity, applicability, clarity, adequacy, and content validity of the study tools and time required to fulfill it and to determine possible problems in the methodological approach or instrument. The results of the pilot study were used to test the proposed statistical and data analysis methods. The tools were completed without difficulty, adding support to the validity of the instrument. Mothers involved in the pilot study were included in the main study sample.

\section{Field work:}

Before conducting the study an official permissions from the directors of Preventive Medicine and Social Center and pediatric arrhythmia outpatient clinic were obtained. The research investigator introduce self to the mothers of children connected with permanent pacemaker who fulfilling the inclusion criteria. Mothers who were met the inclusion criteria were invited to participate in the study. The purpose and the nature of study were explained to each mother on individual bases. A formal written consent was obtained from each mother to get her acceptance as well as to gain her cooperation.

The interview was conducted for all mothers to fill their personal data and characteristics of their children and assessment of mothers' knowledge about care of their children with pacemaker was obtained by the research investigator. Each mother was interviewed individually, the time of the interview ranged from 20 to 30 minutes. Data about pacemaker such as setting, time of implant, follow-up schedule was obtained from the child's medical file. The interview was take place in the waiting area in the arrhythmia out-patient clinic or pacemaker programming clinic during the predetermined follow-up schedule. The follow-up for children with pacemaker was done every Wednesday. Data collection was conducted over four months extending from June till September 2017.

\section{Statistical analysis:}

The collected data was tabulated, and summarized. A statistical package for social studies (SPSS
Version 21) was used for statistical Analysis of data. Data was computerized and analyzed using appropriate descriptive and inferential statistical tests to test the research question. Qualitative data were expressed as frequency and percentage. Correlation among variables was done using correlation coefficient. Level of significance at $p<0.05,0.001$ were used as the cut of value for statistical significance.

\section{Results}

Table (1) clarified that $34 \%$ of the mothers who participated in the current study their age ranged from 25 to less than 30 years. Regarding mothers level of education; it was found that $34 \%$ of the mothers had secondary school education, while $14 \%$ of them were not read and write. More than half $(56 \%)$ of them came from rural areas. Table (2) evident that half $(50 \%)$ of children connected with permanent pacemaker and participated in the current study their age ranged from 3 to less than 5 years, $58 \%$ of them were males. While, $52 \%$ of children were ranked as the second child in their families. More than half $(52 \%)$ of children didn't join kindergarten. The majority $(87.5 \%)$ of their teachers in the kindergarten were informed about the child's disease.

As regards the past history among children connected with permanent pacemaker, Table (3) evident that $36 \%$ of children were connected with permanent pacemaker from $12-<24$ months, with mean $17.44 \pm 13.44$ months. The vast majority $(98 \%)$ of children had Congenital Heart Defect (CHD). Congenital disorder in sinus node and titerology of Fallot were the common CHD among children $(28.6 \% \& 26.5 \%$ in order).

Table (1): Percentage distribution of mothers' personal data $(\mathrm{n}=50)$.

\begin{tabular}{lll}
\hline Personal data & No & $\%$ \\
\hline Agelyears: & & \\
$<20$ & 9 & 18 \\
$20-<25$ & 9 & 18 \\
$25-<30$ & 17 & 34 \\
$30-<35$ & 11 & 22 \\
$35-<40$ & 3 & 6 \\
40 and more & 1 & 2 \\
Level of education: & & \\
Not read and write & 7 & 14 \\
Just read and write & 6 & 12 \\
Basic education & 14 & 28 \\
Secondary school & 17 & 34 \\
University graduate & 6 & 12 \\
Place of residence: & & \\
Rural & 28 & 56 \\
Urban & 22 & 44 \\
\hline
\end{tabular}


Table (2): Percentage distribution of characteristics of children connected with permanent pacemaker $(n=50)$.

\begin{tabular}{lll}
\hline Children' characteristics & No & $\%$ \\
\hline Age/years: & 9 & 18 \\
$<1$ & 16 & 32 \\
$1-<3$ & 25 & 50 \\
$3-5$ & & \\
Gender: & 29 & 58 \\
$\quad$ Male & 21 & 42 \\
$\quad$ Female & & \\
Rank within the family: & 14 & 28 \\
First & 26 & 52 \\
Second & 7 & 14 \\
Third & 3 & 6 \\
More than third & & \\
Kindergarten enrollment: & 24 & 48 \\
Yes & 26 & 52 \\
No & & \\
Teachers informed about & & \\
the child's disease ( $n=24):$ & 21 & 87.5 \\
Yes & 3 & 12.5 \\
No &
\end{tabular}

Table (3): Past history among children connected with permanent pacemaker in percentage distribution $(n=50)$.

\begin{tabular}{lll}
\hline Items & No & $\%$ \\
\hline Duration of pacemaker/months: & \multicolumn{2}{c}{} \\
- 12 & 15 & 30 \\
- $12-<24$ & 18 & 36 \\
- $24-<36$ & 5 & 10 \\
- $36-48$ & 12 & 24 \\
- Mean \pm SD & $17.44 \pm 13.44$ \\
The child had CHD: & \multicolumn{2}{|c}{} \\
- Yes & 49 & 98 \\
- No & 1 & 2 \\
Type of CHD (n=49): & \multicolumn{2}{|c}{} \\
- Congenital disorder in sinus node & 14 & 28.6 \\
- Titerology of Fallot (TOF) & 13 & 26.5 \\
- Atrial Septal Defect (ASD) & 5 & 10.2 \\
- Transposition of Great Arteries (TGA) & 5 & 10.2 \\
- Ventricular Septal Defect (VSD) & 12 & 24.5 \\
\hline
\end{tabular}

Fig. (1) highlighted that the highest percentage (70\%) of mothers in the current study do not recived knowledge about care of their children connected with permanent pacemaker. As regards mothers' knowledge about pacemaker, Table (4) indicated that nearly three quarters $(74 \%)$ of the mothers in the current study didn't know what is pacemaker. More than half $(56 \%)$ of them had no knowledge about the component of pacemaker and $46 \%$ of them didn't know the life span of pacemaker battery.

Table (5) clarified that the highest percentages ( $74 \%$ \& $72 \%$ respectively) of the mothers had incomplete knowledge as regards indications of pacemaker and signs of wound infections. Play is allowed after pacemaker installment as reported by $64 \%$ of the mothers of children connected with pacemaker. More than half (52\%) of the mothers had no knowledge about games that are forbidden to their children after installing pacemaker. Total mean score of mothers' knowledge was $14.58 \pm 9.43$. Fig. (2) demonstrated that more than three quarters $(76 \%)$ of the mothers had unsatisfactory level of knowledge about pacemaker. In relation to mothers' level of reported-care, Fig. (3) showed that the majority (84\%) of the mothers had satisfactory level of reported-care for their children connected with permanent pacemaker. Total mean score of mothers' reported care was $6.14 \pm 1.9$.

Table (4): Mothers' knowledge related to definition, components, lifespan and placement of pacemaker in percentage distribution $(n=50)$.

\begin{tabular}{lll}
\hline Items & No & $\%$ \\
\hline Definition of pacemaker: & & \\
$\quad$ Complete & 5 & 10 \\
$\quad$ Incomplete & 8 & 16 \\
$\quad$ Wrong/didn't know & 37 & 74 \\
Components of pacemaker: & & \\
$\quad$ Complete & 7 & 14 \\
$\quad$ Incomplete & 15 & 30 \\
$\quad$ Wrong/didn't know & 28 & 56 \\
$\quad$ Life span of pacemaker battery: & & \\
$\quad$ Complete & 12 & 24 \\
$\quad$ Incomplete & 15 & 30 \\
$\quad$ Wrong/didn't kow & 23 & 46 \\
\hline
\end{tabular}

Table (5): Mothers' knowledge related to indications of pacemaker, signs of wound infection and play after pacemaker installment in percentage distribution $(\mathrm{n}=50)$.

\begin{tabular}{lll}
\hline Items & No & $\%$ \\
\hline Indications of pacemaker: & & \\
$\quad$ Complete & 8 & 16 \\
$\quad$ Incomplete & 84 & 74 \\
$\quad$ Wrong/didn't know & & \\
Signs of wound infection: & 14 & 28 \\
$\quad$ Complete & 36 & 72 \\
$\quad$ Incomplete & 0 & 0 \\
$\quad$ Wrong/didn't know & & \\
Paly is allowed after pacemaker installment: & 32 & 64 \\
$\quad$ Yes & 18 & 36 \\
$\quad$ No & & \\
Games that are forbidden to the child after & & \\
installing pacemaker: & 10 & 20 \\
Complete & 14 & 28 \\
$\quad$ Incomplete & 26 & 52 \\
$\quad$ Wrong/didn't know & & \\
\hline
\end{tabular}




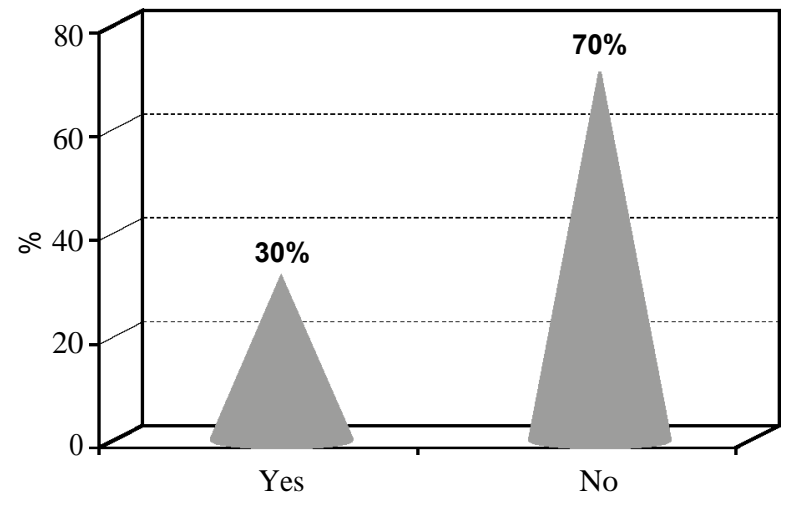

Fig. (1): Have mothers been given knowledge about care of their children connected with permanent pacemaker in percentage distribution $(\mathrm{n}=50)$.

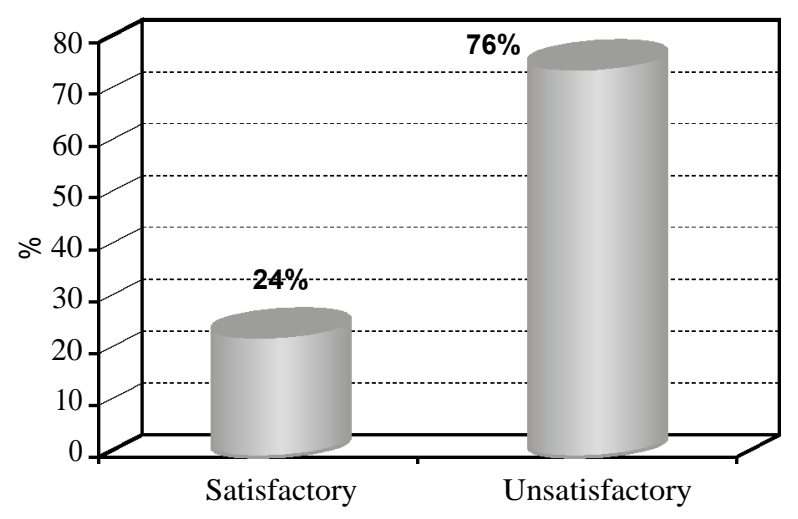

Fig. (2): Mothers' level of knowledge regarding pacemaker in percentage distribution $(n=50)$.

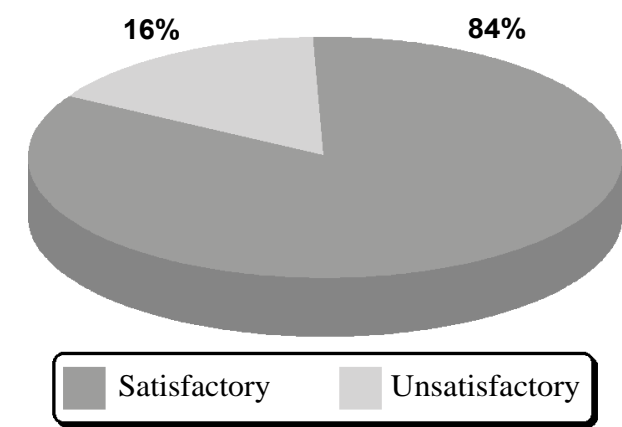

Fig. (3): Mothers' level of reported care for their children connected with permanent pacemaker in percentage distribution $(\mathrm{n}=50)$.

The study results revealed that there were highly statistically significant positive correlations between the total mean score of mothers' knowledge and their level of education, occupation and place of residence $(p=<0.01)$. There was statistically significant positive correlation between the total mean score of mothers' knowledge and their age $(p=<0.05)$. There was highly statistically significant positive correlation between the total mean score of mothers' reported-care and their level of education $(p=<0.01)$. There were statistically significant positive correlations between the total mean score of mothers' reported-care and their age, occupation and place of residence $(p=<0.05)$ (Table 6).

Table (6): Correlation between total mean score of mothers knowledge and reported care and their selected personal data $(\mathrm{n}=50)$.

\begin{tabular}{lccccc}
\hline Personal data & $\begin{array}{c}\text { Total mean } \\
\text { score of mothers' } \\
\text { knowledge }\end{array}$ & \multicolumn{2}{c}{$\begin{array}{c}\text { Total mean } \\
\text { score of mothers } \\
\text { reported-care }\end{array}$} \\
\cline { 2 - 2 } & $r$ & $p$ & & $r$ & $p$ \\
\hline Age & .292 & $.040^{*}$ & .291 & $0.40^{*}$ \\
Level of education & .590 & $.000^{* *}$ & .564 & $.000^{* *}$ \\
Occupation & .393 & $.005^{* *}$ & .304 & $.032^{*}$ \\
Place of residence & .402 & $.004^{* *}$ & .329 & $.020^{*}$ \\
**: Correlation is significant at the 0.01 level. & & \\
*: Correlation is significant at the 0.05 level. & &
\end{tabular}

Table (7) revealed that there was highly statistically significant positive correlation between total score of mothers' knowledge and duration of pacemaker installment $(p=<0.01)$. However, there were no statistically significant correlations between total score of mothers' knowledge and child; age, gender, and rank with the family. There was statistically significant positive correlation between total score of mothers' reported-care and duration of pacemaker installment $(p=<0.05)$ however, there were no statistically significant correlations with the other characteristics of the children.

Table (7): Correlation between total mean score of mothers knowledge and reported care and their children selected personal characteristics $(n=50)$.

\begin{tabular}{|c|c|c|c|c|}
\hline \multirow[t]{2}{*}{$\begin{array}{l}\text { Personal } \\
\text { characteristics }\end{array}$} & \multicolumn{2}{|c|}{$\begin{array}{l}\text { Total mean } \\
\text { score of mothers' } \\
\text { knowledge }\end{array}$} & \multicolumn{2}{|c|}{$\begin{array}{l}\text { Total mean } \\
\text { score of mothers } \\
\text { reported-care }\end{array}$} \\
\hline & $r$ & $p$ & $r$ & $p$ \\
\hline - Age & .194 & .178 & .159 & .271 \\
\hline - Gender & .053 & .715 & -.040 & .783 \\
\hline - Rank & .052 & .722 & .002 & .990 \\
\hline $\begin{array}{l}\text { - Duration of pacemaker } \\
\text { installment }\end{array}$ & .424 & $.002 * *$ & .340 & $.016^{*}$ \\
\hline
\end{tabular}

**: Correlation is significant at the 0.01 level.

* : Correlation is significant at the 0.05 level.

\section{Discussion}

As regards personal data of the mothers and their children connected with permanent pacemaker, the result of the current study indicated that the highest percentage of mothers' age ranged from 25 to less than 30 years. This result was contradicted with a result inferred from a recent Egyptian study held by [16] to evaluate the effect of teaching instructions for mothers of children with permanent pacemaker on their knowledge and selected child's 
outcomes. They found that $46 \%$ of the mothers aged from 30-39 years. On the same context, [17] studied children living with a pacemaker or implantable cardioverter defibrillator in London and found that mothers who had children with pacemaker increased significantly at age (20-24) years as detected in more than one third of the mothers.

Regarding to mothers level education; the result of the current study revealed that more than one third of the mothers had secondary school education. The result reflected that higher literacy rate among Egyptian mothers. On the same line, the Egypt demographics profile (2016) [18] assured that, the literacy rate among females was $63.5 \%$ compared to $59.4 \%$ in 2015 . So efforts of governmental and non-governmental organizations should continue to focus on female' education because low levels of literacy, and education in general, can impede the economic development of a country in the current rapidly changing, technology-driven world, this of course will reflect positively on the health care system as a whole as well as on care provided for sick child.

The current study's results illustrated that more than half of the mothers live in rural areas. This result could be related to the Preventive Medicine and Social Center and CUSPH serve care for children with various types of CHDs in the Cairo metropolitan and surrounding rural and semi-urban areas. On the same context, the United Nations Educational, Scientific and Cultural Organization (UNESCO) (2017) [19], documented that the rural population was $57 \%$ of the total population all over the world. In the same line, [18] documented that urban population was $43.1 \%$ of the total population and the rate of urbanization was $1.68 \%$ annual rate of change.

The results of the current study revealed that half of the children in the study their age ranged from 3 to less than 5 years. These results were supported by [20] who studied the prevalence and risk groups for implemented pacemaker among children in Moscow, and found that the percentage of implemented pacemaker among children increased significantly at age 2-4 years. Additionally, [21] supported the study results and concluded that the children who were implemented pacemaker, aged more than 18 months, while they studied cyanotic CHDs among Nigerian children.

The result of the current study reflected that more than half of children were ranked as the second child in their families and the highest percentage were males. Similarly, [16] found that $48 \%$ of the children who participated in their study were ranked as the middle child and more than three quarters of them were males. The same explanation was reported by [22] found $70 \%$ of children connected with pacemaker were males.

Concerning mothers' knowledge and reportedcare regarding their children connected with permanent pacemaker, the current study results highlighted that the highest percentage of mothers in not given knowledge about care of their children connected with permanent pacemaker, and about thirds of their gained information from physician. The highest percentages of mothers in the study had no knowledge about pacemaker definition, components, lifespan and placement of pacemaker. The maximum percentages of the mothers had had incomplete knowledge as regards indications of pacemaker and signs of wound infections. The above mentioned results could be rationalized as the mothers not informed about the pacemaker as a device and its indications. These results also showed the urgent need for implementation of teaching sessions for mothers about that issue for the provision of safe child's life. On the same context, [11] emphasized that effective nursing teaching for children and their families about knowledge of pacing physiology, components of the pacing system, indications for pacing, postpacemaker implant care, trouble-shooting of pacemaker problems is very important to save child's life and prevent complications from occurrence.

The current study illustrated that more than have of mothers in the study didn't know the risks or problems that their child may have with permanent pacemaker. This result could be related to the diminished knowledge of mothers about complications or problems that their child may have with permanent pacemaker. This result also could reflect the inadequate instructions and information given to the mothers. Mothers' information and knowledge is crucial and constructive in achieving appropriate post pacemaker implantation outcomes and reduction of complications during the child's life with device.

Concerning the mothers' level of knowledge regarding care of their children connected with permanent pacemaker, the current study results demonstrated that more than three quarters of the mothers had unsatisfactory level of knowledge. This result indicates the mothers' need for information and instructions about pacemaker. This result needs to combine all the efforts of the health 
team members to equip mothers with instructions and guidelines to provide safe care for their children with pacemaker. These results were in accordance with [16] who found that $64 \%$ of the mothers had overall unsatisfactory level of knowledge regarding pacemaker.

In relation to the mothers' reported care for their children connected with permanent pacemaker, the current study results revealed that almost two thirds of them provide incomplete care for their child's wound. More than half of them didn't knew how to care for their children when any warning signs. However, more than half of the mothers went to the nearest physician in case of the child had warning signs or hazards. As regards precautions used by the mothers when the mobile phone is used by the child, it was found that the maximum percentage of them avoid long calls. The overall level of the mothers' reported care was satisfactory. This could be due to the fact that the highest percentage of children have been connected to the pacemaker for up to 24 months, so mothers have experience in caring for their children and know how to deal with hazardous devices that affect the function of pacemaker.

In the same field, [23] analyzed the problem of electromagnetic interference between cellular telephones and cardiac pacemakers by looking at the mechanisms by which the radiated radio frequency. They reported that cellular phone signal may affect and disturbs the pacemaker function. They emphasized that any interference on devices such as pacemakers and defibrillators may have serious consequences for the patient.

The current study revealed that there were statistically significant positive correlation between total mean score of mothers' knowledge and total mean score of mother's reported-care and their age, level of education, occupation and place of residence. On contrary, [16] found that there were no statistically significant correlation between mothers' knowledge and their age, while the highest total means score of knowledge was in age from 30-39 years old and high knowledge observed with mother live in urban areas. There were statistically significant positive correlation between total mean score of mother's knowledge and reported care and duration of pacemaker. From my point of view the duration of pacemaker could be affects the mothers' knowledge and highest percentages complications of pacemaker could be found such as arrhythmia, chest pain, dislocation, injuries and loss of battery and this could threat child's life.

\section{Conclusion:}

It was concluded from the current study results that the highest percentage of the mothers had unsatisfactory level of knowledge regarding care of children connected with permanent pacemaker. The majority of the mothers had satisfactory level of reported-care for their children connected with permanent pacemaker. It was concluded also that there were statistically significant positive correlations between the total mean score of mothers' knowledge and reported care and their age, occupation, place of residence and level of education.

\section{Recommendations:}

- Raising the awareness of mothers about care of children connected with permanent pacemaker is mandatory through health education sessions about the pacemaker, child's activities and home precautions.

- Multidisciplinary team including nurses should be involved in developing, implementation and evaluating educational sessions for mothers of children with permanent pacemaker to achieve better outcomes for children.

- Establishing call center and hot lines services in the Preventive Medicine and Social Center is recommended for urgent physician's consultations to facilitate the follow-up of the children connected with permanent pacemaker.

- Future research studies should be done to investigate the factors affecting mothers' level of knowledge related care for their children with permanent pacemaker.

\section{References}

1- University of Oxford: An overview of pacemaker. Available at www.veriware.org/pacemaker. Accessed on 13/12/2016, 2014.

2- ASHFAQ., W., KHAN M., ATIQ M., AMANULLAH M. and MUNEER M.: Dual chamber pacemaker implants-a new opportunity in Pakistan for children with congenital and acquired complete heart block. Journal of Pak Medical Association, 61 (4) p.p. 421-3, 2011.

3- American Heart Association: What is a pacemaker? Available at www.heart.org. Accessed on 13/12/2016, 2015.

4- EPSTEIN A.E., DIMARCO J.P., ELLENBOGEN K.A., ESTES N.A., FREEDMAN R.A. and GETTES L.S.: Guidelines for device-based therapy of cardiac rhythm abnormalities: Journal of the American College of Cardiology, 61 (3), 2013.

5- WELISCH E.1., CHERLET E., CRESPO-MARTINEZ, E. and HANSKY B.: A single institution experience with pacemaker implantation in a pediatric population over 25 years. Pacing and Clinical Electrophysiology, 33 (9): 1112, 2010. 
6- LOTFY W., HEGAZY R., ABD EL-AZIZ O., SOBHY R., HASANEIN H. and SHALTOUT F.: Permanent cardiac pacing in pediatric patients. Journal of Pediatric Cardiology, 34 (2) Doi: 10.1007/s00246-012-0433, 2012.

7- GELDORP V., VANAGT W.Y., PRINZEN F.W. and DELHAAS T.: Chronic ventricular pacing in children: Toward prevention of pacing-induced heart disease. Journal of Heart Failure Review, 16 (3): 305-14, 2011.

8- SAMIR R., DIAB O., MORTTADA A. and ABOULMAATY M.: Permanent pacing in infants and children: A single center experience in implantation and followup. The Egyptian Heart Journal, 63 (3): 183-9, 2011.

9- CZOSEK R.J., MEGANATHAN K., ANDERSON J.B., KNILANS T.K., MARINO B.S. and HEATON P.C.: Cardiac rhythm devices in the pediatric population: Utilization and complications. Journal of Heart Rhythm, 9 (2): 199-208, 2012.

10-Heart Rhythm Society: Guidelines for device-based therapy of cardiac rhythm abnormalities. Available at www. hrsonline. org. Accessed on 10/12/2016, 2012.

11- VERA M.: 6 Pacemaker therapy nursing care plans. Available at www.nurseslabs.com . Accessed on 15/12/ 2016.

12- HOCKENBERRY M.J. and WILSON D.: Wong's Essentials of Pediatric Nursing (10th ed.). USA: Elsevier. 1312, 2015.

13- The Egyptian Cardiac Rhythm Association: The pacemaker kid. Available at www.epsegyp.com . Accessed on 14/12/ 2016, 2016.

14- BECK H., BODEN W., PATIBANDLA S. and MARINE J.: 50th anniversary of the first successful permanent pacemaker implantation in the united states: Historical review and future directions. The American Journal of Cardiology, 106 (6): 810-8, 2010.
15- POLIT D. and BECK P.: Essentials of Nursing Research: Appraising Evidence for Nursing Practice. ed. China: Lippincott Williams \& Wilkins, 2010.

16- IBRAHIM M. and AWAD L.: Effect of teaching instructions on mother' knowledge and selected outcomes among their children having permanent pacemaker. IOSR Journal of Nursing and Health Science, 7 (1): 72-82, 2018.

17- BASS R., PAT S., JONES K.A. and GLENN V.: Pacemaker or Implantable Cardioverter Defibrillator. Available at http://www.chfed.org.uk/congenital-heart-disease-andpacemakers. Accessed on 14/12/2016, 2015.

18- Egypt Demographics Profile: Available at www. indexmundi.com/Egypt, accessed at 15/2/2018, 2016.

19- United Nations Educational, Scientific and Cultural Organization [Unesco] Institute of Statistics: http:// . uis.unesco.org/en/country/eg?theme=education-andliteracyMinistry of Education, Statistical Yearbook 20142015 Accessed in 16/10/2017, 2017.

20- FAROOQI W.O, TALSANIA L.P., HAVMID Z.K. and RINALDI K.H.: The prevalence and risk groups for implemented pacemaker among children. Journal of Heart Failure Review, 16 (3): 305-14, 2015.

21- ANIMASAHUN B.A., MADISE-WOBO A.D. and GBELEE H.O.: Children with transposition of the great arteries: Should they actually be born in Nigeria? World Journal of Cardiology, 9: 277-82, 2017.

22- ALLAM L., NABIH M. and EL-MISSIRY M.: The psychological impact of permanent cardiac pacemakers on pediatric patients and their parents: A case control study. Indian Heart Journal, doi.org/10.1016/j.ihj.2018.02.007, 2018.

23- CENSI F., CALCAGNINI G., TRIVENTI M.N., MATTEI E. and BARTOLINI P.: Interference between mobile phones and pacemakers: A look inside. Ann. Ist. Super. Sanita., 43 (3): 254-9, 2007.

\section{تقيييم معلومات الأمهات المتعلقة برعاية الأطفال المتصلين

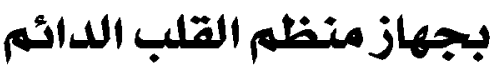

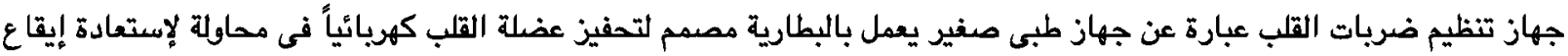

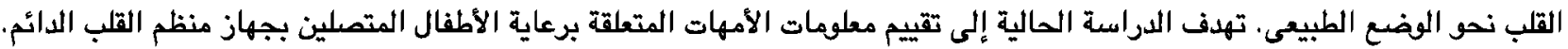

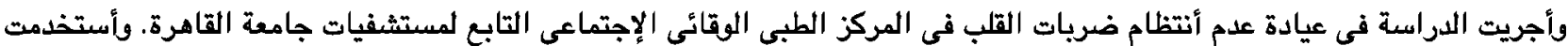

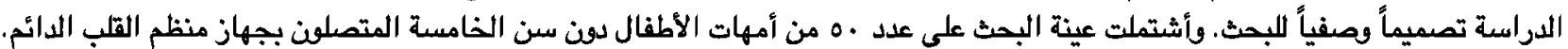

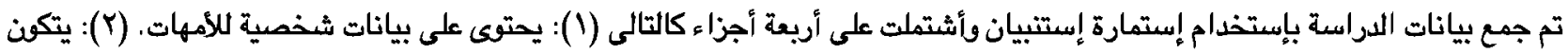

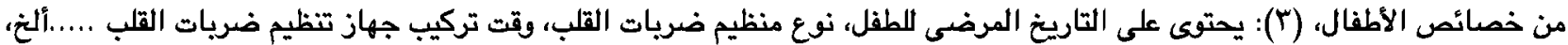

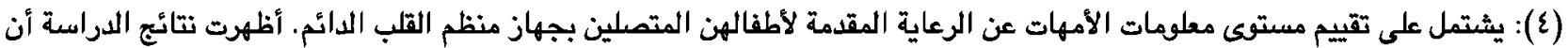

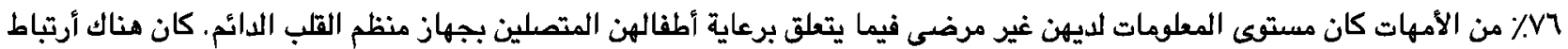

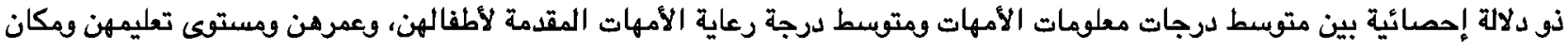

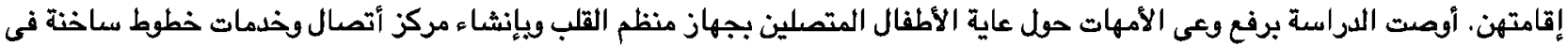

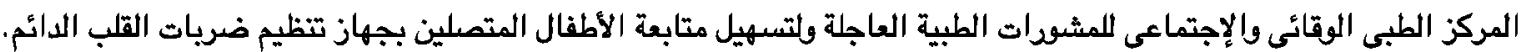

